Article

\title{
Teaching Pre-Service Teachers How to Utilize Web 2.0 Platforms to Support the Educational Needs of Students with Disabilities in General Education Classrooms
}

\author{
Maria B. Peterson-Ahmad ${ }^{1, *}$, Jennifer B. Stepp ${ }^{2}$ and Kyla Somerville ${ }^{3}$ \\ 1 Division of Education and Leadership, Western Oregon University, Monmouth, OR 97361, USA \\ 2 Human Development and Family Studies, Oklahoma State University, Stillwater, OK 74078, USA; \\ Jennifer.Stepp@okstate.edu \\ 3 Division of Education \& Leadership, Western Oregon University, Monmouth, OR 97361, USA; \\ ksomerville16@wou.edu \\ * Correspondence: petersonahmadm@wou.edu; Tel.: +1-(503)-838-9286
}

Received: 15 May 2018; Accepted: 31 May 2018; Published: 2 June 2018

\begin{abstract}
It is without question that technology in schools is here to stay. Educators have always been interested in the extent to which technology can be used to transform education and enhance student learning; however, the degree to which it is utilized in teacher preparation programs for pre-service teachers in terms of Web 2.0 use with future students is under debate. Web 2.0 use can be a particularly interesting tool for teachers to use in differentiating instructional strategies for students with disabilities in inclusive settings. Therefore, it is worthwhile for teacher preparation programs to look at how Web 2.0 platforms can further support students in special education in such settings. The following study delineates data from a study of $\mathrm{N}=82$ pre-service teachers. Throughout the course of this study, all students were administered a pre- and post-survey that asked questions specific to current knowledge of Web 2.0 and the extent to which they thought it could be used in their future teaching practices. In addition, all students completed an assignment within their respective courses that embedded a specific Web 2.0 component. This assignment required pre-service teacher candidates to utilize the Pinterest platform to find and 'pin' educational materials specific to students with whom they will work with in future inclusive classrooms, relative to the various categories of special education.
\end{abstract}

Keywords: inclusion; pedagogy; pre-service teacher; special education; Web 2.0

\section{Introduction}

Learning how to teach is an art, one that is continually crafted year after year of being in a classroom. Similarly, teaching is something that cannot be fully mastered prior to the completion of a teacher preparation program at a university. However, strong preparation can enhance pre-service teachers' abilities to effectively utilize instructional strategies with their students. Through strong preparation, pre-service teachers can enter their future classroom feeling prepared to utilize technology as a form of instruction. One form of instruction that is used to support pre-service teachers in pedagogical preparation is Bloom's Taxonomy. Bloom's Taxonomy is a framework used by educators to develop a knowledge-building pedagogical (the method and practice of teaching) interchange between teachers and students [1]. Bloom's Taxonomy consists of six major categories: knowledge, comprehension, application, analysis, synthesis, and evaluation. Use of this framework allows pre-service teachers to develop strong pedagogical practices in the development of effective lessons. By utilizing Bloom's Taxonomy with Web 2.0, 
pre-service teachers acquire the foundation to support learners with new technology experience and, at the same time, construct new knowledge with set objectives.

In teacher preparation programs, pre-service teachers learn extensively about pedagogy and related teaching practices. Pedagogy relates to how a teacher's actions, judgments, and teaching strategies are taken into consideration in conjunction with what they also know about theories of learning, specific student needs, and the backgrounds and interests of individual students. Pedagogy is vital because it taps into the differentiated instruction that is needed for each student in any given classroom. Although pedagogy may take years to fine tune, it's important to reinforce a variety of strategies and concepts to pre-service teachers as complete their teacher preparation programs.

\subsection{Web 2.0}

Web 2.0 emerged around 2004 and is generally attributed to O'Reilly [2]. It encompasses a variety of different meanings that include an increased emphasis on user-generated content, data and content sharing, and collaborative effort in conjunction with the use of various kinds of social software, new ways of interacting with web-based applications, and the use of the web as a platform for generating, re-purposing, and consuming content [3]. It also allows individuals to collaborate with one another and contribute to the authorship of content, customize websites for specific uses, and instantaneously publish thoughts $[4,5]$.

Howe [6] categorizes four general types of processes within Web 2.0 applications that reflect these types of interactions: (1) the sharing of user-contributed content (you make it); (2) the evolution of community-developed tagging and organizational schemes for large sets of user-contributed content (you name it); (3) the development of content collections by the user community (you work on it); (4) the discovery of objects, trends, and overviews of contributions (you find it). Examples of Web 2.0 platforms include: wikis, social networks, podcasts, and virtual worlds (to name a few). Overall, Web 2.0 technologies emphasize an increased emphasis on user-generated content, data and content sharing, collaborative efforts, new ways of interacting with Web-based applications, and the use of the Web as a social platform for generating, repositioning, and consuming content [7].

Pinterest is one specific example of a Web 2.0 platform. Pinterest is a social network and is essentially a 'virtual corkboard' in which users may browse a broad array of categories, including educational items that we will be discussing for this specific study. Users can conduct a specific search to find 'pinned' ideas that other users have created and/or shared on their Pinterest boards including: websites, specific tangibles (worksheets, games, craft ideas), student motivators, etc. One advantage in using Pinterest is that users can save content and refer to it later. Essentially, Pinterest allows Howe's [7] processes to occur in a way that is dependent on how a teacher creates a particular assignment and/or how the student interacts with the platform including: (a) the creation of a Pinterest board and the sharing of user content ('you make it'); (b) the organization of materials from a pool of materials, refining these materials on Pinterest boards which are specific to a theme, genre, or category of intended choice ('you name it'); (c) allowing others to share in the creation of a collective matter on a Pinterest board or assigning the creation of a group Pinterest board project with specific parameters ('you work on it'); and (d) the search for specific items in Pinterest and conducting an simple analysis on common and/or popular 'pins' ('you find it') [7].

\subsection{Inclusive Classrooms}

Today, general education classrooms have a vast variety of students that make up their student population. Included in this population are students with disabilities. The Individuals with Disabilities Act (IDEA) is a federal law that requires schools to serve the educational needs of eligible students with disabilities. Part B of this law requires schools to assure students with disabilities a free and appropriate public education (FAPE) and that schools have procedures in place to provide students with disabilities an education in the least restrictive environment (LRE). Specifically, IDEA states that, 
"... to the maximum extent appropriate, children with disabilities, including children in private or public institutions or other care facilities, are educated with children who are not disabled, and that special classes, separate schooling, or other removal of children with disabilities from the regular educational environment occurs only with the nature of or severity of the disability is such that education in regular classes with the use of supplementary aids and services cannot be achieved satisfactorily" (IDEA, 2004, 20 USC 1412(a)(5) and regulations are 34 CFR 300.114-300.12) [8].

Students receiving special education services and who spend a majority (if not all) of their day in the general education classroom may require specific accommodations or modifications for their learning. General education teachers are required to abide by what is set forth in an individualized education program (IEP), a legally binding document which requires adherence from all school personnel working with the student, meaning that what is agreed upon in the IEP must be followed. Within an IEP, accommodations and/or modifications are included that are specific to the individualized needs of the student. Accommodations may include: changes in timing, formatting, setting, scheduling, response, and/or presentation [9]. Modifications may include completing work as part of a standard assignment or completion of an alternate assignment that is differentiated and more easily achievable than the original assignment [9] so that the student has various options to complete in a format specific to their individual needs.

\subsection{The Differentiated Needs of Students with Disabilities}

Differentiation may be conceptualized as a teacher's response to the diverse learning needs of a student and is based on the need for teachers to differentiate instruction to meet the needs of diverse learners in a general education class $[9,10]$. Although the differentiated needs for students with disabilities is vast, it is first important to recognize common characteristics that may be noted from students with disabilities in an inclusive general education classroom where students with and without disabilities learn together. In an inclusive classroom, some of the most common characteristics seen in students with disabilities include: deficits in completing multi-step tasks, lack of organization, and reduced engagement in learning tasks. Such characteristics are important to take into consideration because they tie directly to the importance of differentiation. Teachers must know how to tailor instruction to meet the specific needs of learners with disabilities in a general education classroom. Utilizing a Web 2.0 platform (such as Pinterest) with students on IEPs in general education inclusive classrooms is one way to enhance academic instruction specific to individualized instructional needs.

\subsection{Use of Web 2.0 in Teacher Preparation Programs}

Web 2.0 platforms in higher education have claimed to be effective in connecting people and resources, facilitating interaction, fostering collaboration and active participation, and aiding opportunities for critical thinking, among others [11-14]). Attwell [15] hypothesized that "educational systems and institutions are developed to meet the needs of society" at some particular time and that "industrial revolutions lead to profound and often paradigmatic social change" (p. 1). Navigating vast amounts of information requires different skills than those that were needed prior to the development of Web 2.0 meaning that organizing and synthesizing multiple repositories of information must be taught and monitored to ensure accuracy and course/assignment relevancy.

Park (2009) [16] indicates that knowing the factors that influence students' intentions and beliefs about e-learning could help academic managers to design better scenarios that favor the adoption of this type of learning approach. Embedding Web 2.0 assignments into teacher preparation coursework must be mindful and well developed. One method specific to Web 2.0 is the process of participatory pedagogy. The process of participatory pedagogy can be broken down into five steps: (1) instructors require students to use the digital devices in the classroom; (2) instructors present course material and have students interact with it on their devices; (3) students interact with the material, exhibiting certain behaviors while using the technology; (4) instructors observe and record these behaviors, 
which indicate how students address issues, solve problems, contribute ideas, and ultimately learn; (5) through these behaviors, instructors and students have created a new methodology for learning with devices [17,18]. Before assignments that include Web 2.0 usage in higher education can be successful, the following parameters need to be put in place: (1) both instructors and students must value an educational approach where learner participation and contribution are balanced with acquisition; (2) a pedagogical approach must be used that reflects contribution-oriented activities in which students create some of their own learning experiences; (3) the approach must be scaffolded in practice through the interlinking of support resources for both instructors and students, reducing uncertainty as much as possible; (4) both the processes and products produced by the students must be assessed as part of overall course assessment practices [19].

Web 2.0 platforms in higher education have claimed to be effective in connecting people and resources, facilitating interaction, fostering collaboration and active participation and aiding opportunities for critical thinking, among others; however, for Web 2.0 tools and processes to become embedded in mainstream practice in teacher preparation programs, they must be seen as adding significant quality to instructional processes. This, in turn, involves several aspects, including pedagogical approach, instructional integration and support, and assessment [20]. Web 2.0 tools may be used to encourage knowledge generation and social interaction among teachers in preparation [20].

\section{Materials and Methods}

Participants in this study included N = 82 (67 females and 15 males) undergraduate pre-service teachers located in a university in the southern region of the United States, ranging in age between 20 years old and 50 years old. The duration of the study lasted one semester (16 weeks) and all participants completed a pre- and post-Likert rating scale containing 10 questions that sought to understand the extent to which pre-service teachers understood or utilized Web 2.0 platforms, their use with students with and without disabilities, and the extent to which courses in teacher preparation coursework sought to instruct or implement the potential for using Web 2.0 tools and/or platforms. The study was conducted and approved by the Institutional Review Board of the respective university in which the researchers were employed. All participants gave their informed consent for inclusion in this study prior to participation.

Two major research questions were explored throughout this study including:

1. To what extent are pre-service teachers familiar with Web 2.0 for use in classrooms.

2. Can pre-service teachers utilize the Pinterest Web 2.0 platform to assist in individualizing teaching for students with disabilities in an inclusive classroom.

Examples of statements that participants rated included: (a) I am familiar with Web 2.0 platforms; (b) I am confident in Web 2.0 platforms into K-12 classrooms; (c) I feel that Web 2.0 platforms can assist students with disabilities, etc. Throughout the semester, participants worked on a course-specific assignment that allowed for the investigation of potential teaching materials and resources specific to students in varying categories of special education. These potential resources were found using the Web 2.0 platform Pinterest. In the post-rating scale, participants had the option to add a reflection on their experience with the Web 2.0 assignment which they completed over the course of the semester.

Data collected from participants was analyzed using a mixed-methods concurrent triangulation design so that both descriptive data and reflective responses could be used for cross-validation and more accurately define relationships among variables of interest [21]. Descriptive data was extracted from Likert ratings of participants and was coded and assigned numeric values based upon the value each participant assigned to each question. Participants could rate their answers on a 1-5 scale (1-Strongly Disagree, 2-Disagree, 3-Undecided, 4-Agree, 5-Strongly Agree). Trends and related distributions were analyzed to provide descriptive data, resulting in the visual representations found in Figure 1. Qualitative data was taken from pre-/post-open-ended reflective questions and was organized and hand-coded, which allowed the researchers to find common themes and codes. The data was also uploaded to NVivo 
to look for related themes and word choices, resulting in a visual representation of participant answers, as shown in Figure 2. Lastly, triangulation of data was conducted to formulate an overall conceptual framework to explain data collected and depict major findings (see Figure 3).

\section{Results}

In the initial phase of the study, the researchers began their respective pre-service teacher university classes at the beginning of the semester. No detailed information on Web 2.0 was provided to the pre-service teachers prior to administering the pre- rating scale; this potentially removed any bias in answers because students had not yet experienced class lectures or discussed specificities of assignment information on what Web 2.0 was or how it could be used. Participants were asked to rate (on both the pre- and post-rating scale) statements such as: Q1- 'I use Web 2.0 tools on a regular basis' and Q2- 'I use Web 2.0 tools with ease'. The largest increases between pre- to post-rating were seen in the answers to these two questions. The pre-rating mean for Q1 was 2.1, with a post-rating mean of 4.7. Similarly, for Q2, the pre-rating mean was 2.2, with a post-rating mean of 4.5. Q3- asked participants to rate their confidence in how to incorporate Web 2.0 tools into K-12 classrooms. This question also had a vast difference between pre- and post-ratings, with a mean of 2.1 (pre-) and 4.3 (post-), respectively. To gather additional information on the pre-rating scale, participants were asked to list what Web 2.0 tools they were familiar with; responses indicated that 80 participants had zero knowledge of Web 2.0. This pre-rating scale also informed the researchers that two participants had limited knowledge of the Web 2.0, which indicated their knowledge social media, PowerPoint, and Prezi.

When asked to rate whether or not Web 2.0 tools should be incorporated into K-12 classrooms, participants were undecided on the pre- rating scale (mean 3.0) but had vastly changed their minds on the post-scale, with a mean of 4.5. There was a specific statement regarding whether or not Web 2.0 tools could assist students with disabilities. Participant ratings on the pre-scale also indicated that they were undecided, with another mean of 3.0. Again, there was an increase on the post-scale with a mean of 1.6, with an overall mean score of 4.6. Overall, participants agreed that Web 2.0 tools were useful for all students, with a pre-rating mean of 2.9 and a post-rating mean of 4.7. The trend line in Figure 1 confirms that $100 \%$ of participant pre- to post-responses in the Likert scale statements increased in agreement regarding the extent to which they felt that Web 2.0 platforms were a useful and viable tool to use in inclusive classroom settings with all students.

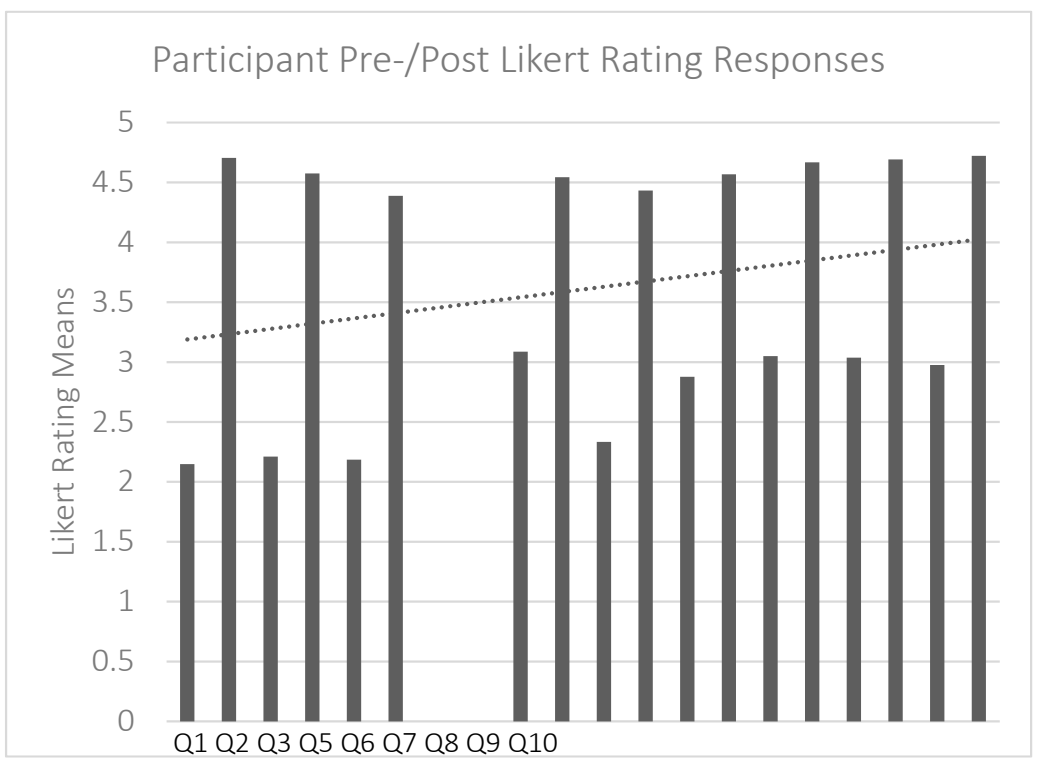

Figure 1. Participant Likert ratings between pre-/post-responses (1-strongly disagree to 5-strongly agree). 
Participants also had the opportunity to add reflective and personal thoughts regarding Web 2.0 during both the pre- and post- the rating scale. This information was analyzed to determine trends in participant exposure both prior to and following the completion of their Web 2.0 class assignment.

Researchers found three notable trends from the pre- to post-rating scale. Answers from participants in the pre-rating scale indicated that they were overall unaware of Web 2.0 and its purpose in the classroom. No additional comments were provided by participants on the pre-rating scale; however, post-rating scale comments from participants indicated that new knowledge was constructed regarding the utilization of Web 2.0. Trends that emerged from data analysis of the open-ended response question regarding Web 2.0 use within classrooms indicated that, overall, participants found Pinterest to be a very useful application for locating educational and classroom applications.

Secondly, data indicated that participants learned how to utilize the Web 2.0 platform (specifically Pinterest) with greater ease than at the beginning of the semester. For example, one participant stated in the pre-rating scale that, "I have no idea what Web 2.0 is". In the post-rating scale rating, this view on the efficacy of Web 2.0 had changed dramatically, "Before this semester I had no idea what web 2.0 was. Now I've realized one of many ways to incorporate it into learning for all students!" Another participant, who made the following pre-rating scale statement, "I know what Web 2.0 is, but I don't see where it could ever be useful in a classroom", also hand a mindset shift throughout the semester, indicated by their post-rating scale statement, "Most of the Web 2.0 technology I am familiar with I learned this semester, but it has completely changed my entire perspective on using technology in the classroom. I now see where I could totally use this in my future classroom." Overall, the data indicated that a majority of the participants drastically shifted their knowledge of and thought process for how Web 2.0 could be used in their future classrooms to support students with and without disabilities.

Lastly, data indicated that participants found the utility of platforms like Pinterest and other Web 2.0 platforms as an extreme benefit to their future classrooms. Through the data analysis, participants had an overall increase in knowledge of Web 2.0 and the benefits of using it as a platform of instruction. Figure 2 depicts a visual depiction of word frequency from open-ended response reflections from participants on the post-rating scale.

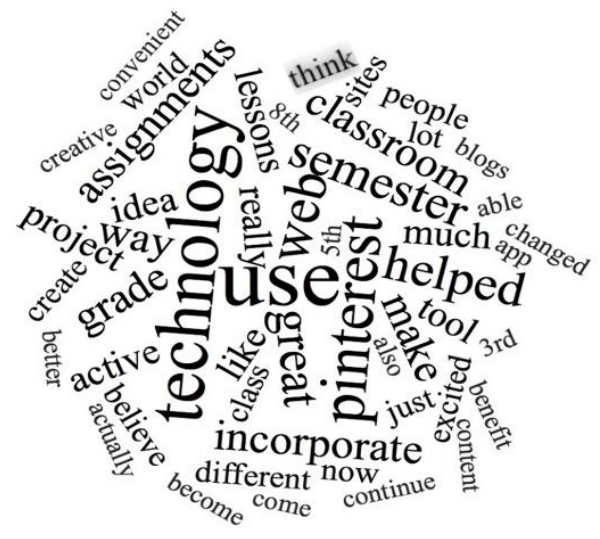

Figure 2. Participant most frequently used reflection words in a post-scale open-ended question regarding the efficacy of Web 2.0.

\section{Discussion}

Valuable information was discovered through this research study. When looking specifically at our first research question: To what extent are pre-service teachers familiar with Web 2.0 overall for use in classrooms? We found that a low number of our participant group was not familiar with Web 2.0 platforms at the beginning of the study. Pre-rating scale data indicated that a majority of participants rated 'disagree' in regards to their familiarity with Web 2.0 and its use in classroom settings. One main reason why we presume that this particular group of participants may have rated 'disagree' in 
terms of lack of familiarity to Web 2.0 was a lack of access to technology. This may stem from both the location of this university setting and the demographics of its student population, a majority of whom are first-generation college students. This population of students also had limited resources, which hindered them from engaging and exploring technology.

This study also allowed us to glean information regarding our second research question: Can pre-service teachers utilize the Pinterest Web 2.0 platform to assist in individualizing teaching for students with disabilities in an inclusive classroom? Descriptive and qualitative data confirmed that, yes, pre-service teachers successfully utilized and gained extensive knowledge both with Pinterest and with Web 2.0 generally. Throughout the semester, in learning about Web 2.0 and differentiation strategies for students with disabilities, the completion of Pinterest board assignments by the participants revealed a concrete application of learned concepts regarding knowledge of strategies to find and teach students with disabilities. In addition to the Pinterest board creations, students also reflected upon how Web 2.0 solidified their understanding of inclusive strategies and practices for their future classrooms and the vast array of students with and without disabilities who will be members of inclusive classrooms. By exploring Pinterest, pre-service teachers expanded their knowledge of various instructional strategies by finding multiple ways that supported strong pedagogy for future teaching.

Lastly, triangulation of descriptive and qualitative responses indicated three main factors to take into consideration when implementing effective teaching and use of Web 2.0 in any educational setting. The first is to provide explicit instruction on defining Web 2.0 and its potential uses in an inclusive classroom, requiring a degree of mindfulness as to how a teacher should set up particular Web 2.0 experiences for students with and without disabilities in the classroom. It is imperative that there are explicit guidelines for any given Web 2.0 assignment and/or learning experience so that students have a framework of understanding both the purpose and scope of the assignment. Once guidelines are created, it is best for the educator to model several examples as to how to use the given platform so that students have opportunities to ask clarifying questions. Next, students must be given the opportunity to practice using Web 2.0 technology prior to beginning the assignment on their own. Once students have practiced and the educator has ensured that clarifying questions have been addressed, students can further their Web 2.0 practice by beginning the specific assignment or task. It is essential that the educator provides specific feedback before, during, and after the assignment or task to continue assurance that the Web 2.0 platform is being utilized correctly and/or appropriately for the given assignment. Students can also provide peer support to one another by completing Web 2.0 assignments/tasks in a group or by sharing their products with one another. (see Figure 3).

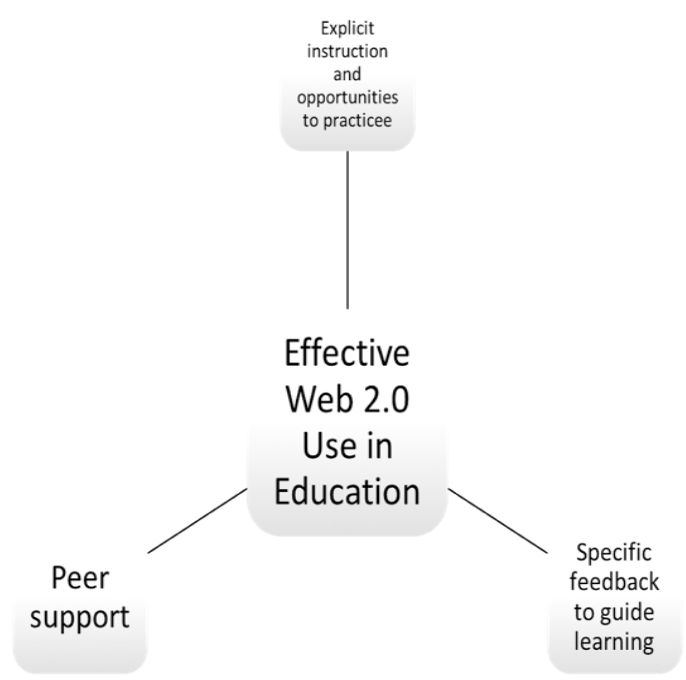

Figure 3. Three main factors in effective Web 2.0 use in education found through a triangulation of findings. 


\section{Conclusions}

To reduce the risk of any negative consequences in terms of program and course quality, the following recommendations can be made: (1) stimulate a well-managed approach to the embedding of Web 2.0 tools and processes within course learning activities by providing support for instructors in appropriate management and assessment practices; (2) stimulate an environment in which digitally literate students are supported and encouraged in their use of Web 2.0 tools and processes; (3) develop institutional procedures and guidelines for the use and reuse of learning resources from professional providers and those contributed by students (p. 102) [20].

There are multiple opportunities for adapting technology to make it suitable for students in special education-specific contexts (such as inclusive classroom) that address individualized educational needs. Web 2.0 technologies can provide this foundation for the development of a new mode of educational practice, one that is participatory and relies on digital innovation in the classroom [19]. How to suitably prepare Web 2.0 experiences for students in special education depends on the extent to which teacher preparation programs embed such experiences into coursework. The incorporation of Web 2.0 technologies in higher education should be deployed in a way that enhances teaching and learning and does not hinder pedagogy [8]. To accomplish this, teacher preparation faculty must understand the purpose of Web 2.0 technologies and how to effectively embed such technologists into course assignments and/or experiences for maximum effectiveness. When done correctly (such as the method used in this study), pre-service teachers can learn significant amounts of knowledge as to how to differentiate and individualize for students with disabilities and make learning more fun and engaging.

Author Contributions: M.P.A. and J.B. S contributed equally to the overall development and data collection for this research study. M.P.A., J.B.S., and K.S. contributed equally to the conceptualization and writing of this article.

Funding: This research received no external funding.

Conflicts of Interest: The authors declare no conflict of interest.

\section{References}

1. Bloom, B.S. Taxonomy of Educational Objectives: The Classification of Educational Goals; Longmans, Green \& Co. LTD.: London, UK, 1969; ISBN 13: 978-0582280106.

2. O'Reilly, T. What Is Web 2.0: Design Patterns and Business Models for the Next Generation of Software. Available online: https://www.oreilly.com/pub/a/web2/archive/what-is-web-20.html (accessed on 20 March 2018).

3. Franklin, T.; van Harmelen, M. Web 2.0 for learning and teaching in higher education. Bord. High. Educ. 2007. Available online: https://pdfs.semanticscholar.org/24ba/620460a6db0bd9284aabf8e286be62ddb77f.pdf (accessed on 15 April 2018).

4. Alexander, B. Web 2.0: A new wave of innovation for teaching and learning? Educ. Rev. 2006, 41, 32-44.

5. Heafner, T.L.; Friedman, A.M. Wikis and constructivism in secondary social studies: Fostering a deeper understanding. Comp. Schools 2008, 25, 288-302. [CrossRef]

6. Howe, J. Your web, your way. Time 2006, 168, 60-63.

7. Harris, A.; Rea, A. Web 2.0 and virtual world technologies: A growing impact on education. J. Inf. Syst. Educ. 2009, 20, 137-144.

8. Individuals with Disabilities Education Act. Public Law 94-142. In Encyclopedia of Clinical Neuropsychology; Springer: New York, NY, USA, 2011.

9. Pacer Center. School Accommodation and Modification Ideas for Students Who Receive Special Education Services. Available online: http:/ / www.pacer.org/parent/php/PHP-c49a.pdf (accessed on 2 April 2018).

10. Tomlinson, C. The Differentiated Classroom: Responding to the Needs of All Learners; Association for Supervision and Curriculum Development: Alexandria, VA, USA, 1999; ISBN 978-0871203427.

11. Tomlinson, C. How to Differentiate Instruction in Mixed Ability Classrooms, 2nd ed.; Association for Supervision and Curriculum Development: Alexandria, VA, USA, 2001; ISBN 978-0131195004.

12. Romero-Frías, E.; Arquero, J.L. A View on personal learning environments through approaches to learning. Innov. Qual. Learn. 2013, 1, 29-36. 
13. Ajjan, H.; Hartshorne, R. Investigating faculty decisions to adopt Web 2.0 technologies: Theory and empirical tests. Int. High. Educ. 2008, 11, 71-80. [CrossRef]

14. Mason, R. Learning technologies for adult continuing education. Stud. Contin. Educ. 2006, 28, 121-133. [CrossRef]

15. Attwell, G. Web 2.0 and the changing ways we are using computers for learning: What are the implications for pedagogy and curriculum? Eur. Union 2007. Available online: http:/ / citeseerx.ist.psu.edu/viewdoc/ download?doi=10.1.1.122.6064\&rep=rep1\&type=pdf (accessed on 17 April 2018).

16. Park, S.Y. An Analysis of the technology acceptance model in understanding university students' behavioral intention to use e-learning. Educ. Technol. Soc. 2009, 12, 150-162.

17. Grandon, E.; Alshare, O.; Kwan, O. Factors influencing student intention to adopt online classes: A Cross-cultural study. J. Comput. Sci. Coll. 2005, 20, 46-56.

18. DePietro, P. Transforming Education with New Media: Participatory Pedagogy, Interactive Learning and Web 2.0; Peter Lang: New York, NY, USA, 2013; p. 4, ISSN 1058-1634.

19. Collis, B.; Moonen, J. Web 2.0 tools and processes in higher education: Quality perspectives. Educ. Media Int. 2008, 45. [CrossRef]

20. Albion, P.R. Web 2.0 in teacher education: Two imperatives for action. Comput. Schools 2008, 25, 181-198. [CrossRef]

21. Creswell, J.; Plano Clark, V.; Gutmann, M.; Hanson, W. Advances in Mixed Methods Research Designs; Sage: Thousand Oaks, CA, USA, 2003; pp. 209-240.

(C) 2018 by the authors. Licensee MDPI, Basel, Switzerland. This article is an open access article distributed under the terms and conditions of the Creative Commons Attribution (CC BY) license (http://creativecommons.org/licenses/by/4.0/). 